\title{
Combining Satellite and Geospatial Technologies for Rainstorms Hazard Soft Mapping
}

\author{
Nazzareno Diodato $^{1, *}$ and Michele Ceccarelli ${ }^{2}$
}

\author{
${ }^{1}$ Technologies Interdepartmental Center for Environmental Diagnostic and Sustainable Development - TEDASS Uni- \\ versity of Sannio, Piazza Arechi II - 82100 Benevento (Italy) \\ ${ }^{2}$ Research Center on Software Technologies-RCOST, University of Sannio-via Port'Arsa, 11-82100 Benevento (Italy)
}

\begin{abstract}
Multiple Damaging Hydrological Events are rapidly developing into worldwide disasters with effects to the viable habitat for humankind and ecosystems. This research describes how data assimilation friendly models combining remotely sensed and ground hydrological data could be used for developing a soft geovisual communication in order to reduce the uncertainty in rainstorm hazard mapping. For this, a set of sequential GIScience rules was utilized for converting coding data of a Rainstorm Hazard Index (RHI) from point record to spatial information using TRMM-NASA satellite rain data as covariate. Examples of probability estimation for different precipitation durations, ranging from 3 to 48 hours and the quantification of hydrological hazard fields were used with probability maps of damaging rainstorms prone-areas for the test-region of Southern Italy. Results show that sub-regional rainstorm hazard modelling can provide probability maps for damaging events in Italy with a spatial variability resolution of around $20 \mathrm{~km}$. Spatially finer estimates (e.g., at local-scale: $<10 \mathrm{~km}$ ) can be ensured only with the availability of more accurate and detailed remote sensing rain data.
\end{abstract}

Keywords: Rainstorm hazard, GIScience, Tropical rainfall measurement mission (TRMM), Multiple damaging hydrological events (MDHE), Probability map.

\section{INTRODUCTION}

Multiple Damaging Hydrological Events (MDHE - [1]) are rapidly developing into deluges, flash floods, floods, mudflows, accelerated erosion, and landslides [2, 3], with tragic consequences on the viable habitat for humankind and ecosystems, and agriculture [4]. In this context, MDHE could have more impact than the frequently cited hazard of global warming due to intensification of the hydrological cycle and the concentration of rainfall in sporadic- but more intense events [5].

There is, in fact, evidence available from different parts of the world of a rising trend of natural disasters since 1993 [6]. For Southern Italy, the catastrophic events of Sarno in 1998 [7], and the more recent devastating deluges in Naples in 2001, 2003, 2004, and 2006, caused by extreme weather events are examples. Therefore, global vision in remote sensing coverage and surveillance loop are important, since we do not know where an event might take place [8]. However, while terrain information such as land cover, geology, geomorphology, and drainage has been frequently derived from satellite images for predicting causative hazard parameters, satellite-based rainfall estimate, landscape stress patterns and their estimates of relative spatial uncertainty for assisting development of a hydrological hazard model, are very few [after 9-11]. Also while the literature on general model theory is vast, the aims of modellers usually consist of improving our understanding of a phenomenon and its process, and ultimately predicting the response of the landscape [after

*Address correspondence to this author at the Technologies Interdepartmental Center for Environmental Diagnostic and Sustainable Development TEDASS University of Sannio, Piazza Arechi II - 82100 Benevento, Italy; E-mail: scodalabdiodato@gmail.com
12]. This is particularly so, because estimating rainfall from satellite imagery is rather complex [13], and due to limited success of deterministic rainstorm impact modelling techniques [14]. In this context, data assimilation models, that combine ground data with remote sensing observations raindata, need to accommodate many specific aspects of the observations and models [15]. While surface data will always remain important cornerstones of reference for monitoring and modelling geospatial data, ground data suffers especially due to mutability of their patterns, even as the modeller is compelled to adapt frequently to maintain sufficient condition of temporal and spatial homogeneity, with time-series that are difficult to update.

The advent of Geographical Information Science (GISsci) can confer an innovative role on hazard modelling development, satellite data assimilation, model outputs uncertainty assessment, spatial data scaling, and mapping visualization. Although satellite data are regarded as indirect information and not as reliable as surface data, they can be of great help when used for scaling and assisting the modelling of a dynamic system [16]. However, the problem is that we have a significant increase in uncertainty when the measurements and forecasts move from the global to local scale, especially in their landscape response to change, such as downpours, heavy runoffs and flash-floods, deluges, sediment transport, and urban stormwater [after 17]. An interesting study for assessing rainfall impact was recently done by [18] that analyzed precipitation with the parametric geostatistical approach in order to obtain information for predicting natural hazards caused by heavy rains.

In this paper, a different geostatistical criterion was applied - specifically a non-parametric approach - by transforming ground and satellite information into a continuous 


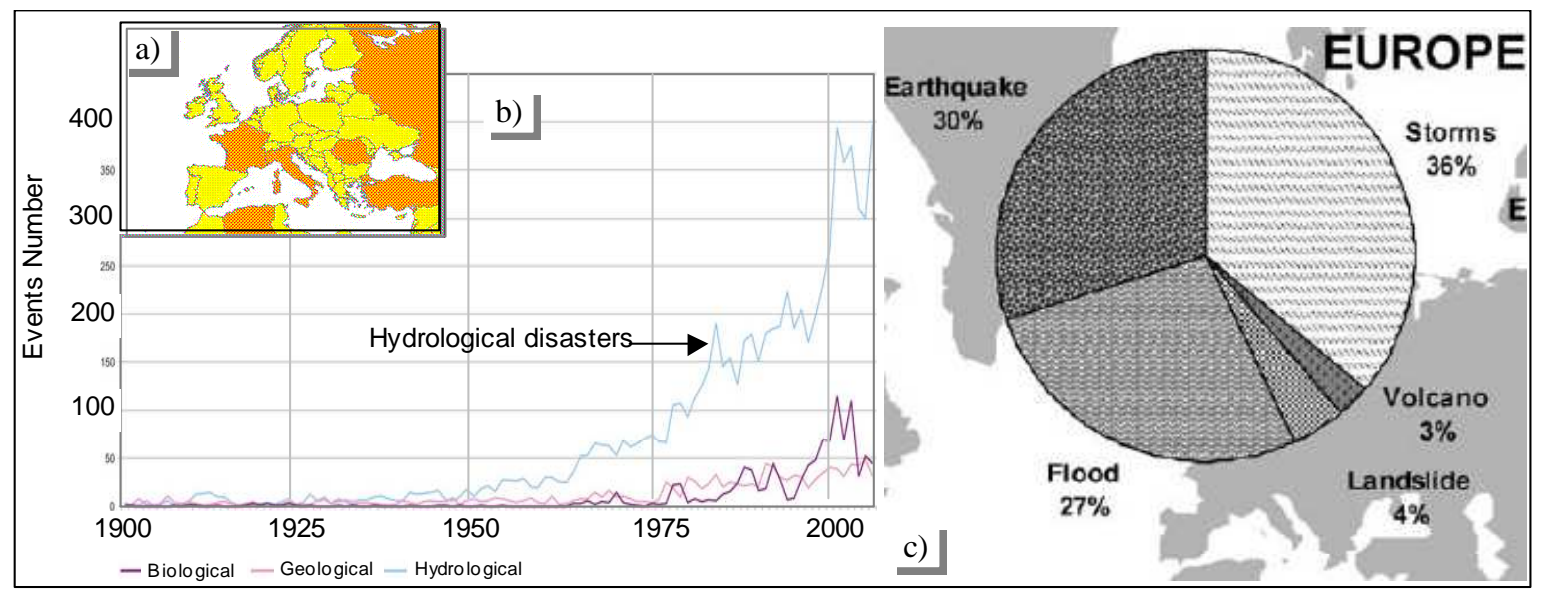

Fig. (1). (a): Flood Disasters by Country: 1974-2003, from EM-DAT database (http://www.emdat.be/); b): natural disasters trends 19002005, from EM-DAT (OFDA/CRED International Disaster Database, http://www.em-dat.net); and c): percentage of geomorphology related disasters by type and region from 1900 to 1999 (from Alcántara-Ayala, 2002, modified).

probabilistic response consistent with soft descriptions of hazards which is referred to in this study to mitigate the uncertainties in downscaling and geocomputational tracking (e.g., spatio-temporal non-homogeneity in the primary variable pattern, accuracy of the supplementary variables, errors involving sampling and hazard modelling). Processes operating to these multiple spatial and temporal scales, however, challenge the predictive capability of environmental models and integration or scaling of data from different sources [19]. Non-parametric geostatistical multivariate analysis, via coindicator coding criteria, is able to combine rainstorm indicators (which are recorded at sparse raingauge station-points) and supplementary satellite rain data (which are recorded at regular grid-points). So that, the novelty of our approach lies in how methods and different tools might incorporate uncertainty associated with satellite data into a model of rainstorm hazard accounting, and to illustrate how model performs at sub-regional scale. In this way, the expansion of a Rainstorm Hazard Index $(R H I)$ data from point to spatial information can be assessed with the Indicator CoKriging (ICK) technique, using Tropical Rainfall Mission Monitoring (TRMMNASA) satellite rain data as covariate. Thus, spatial information is visualized with examples of probability estimations for different precipitation durations - ranging from 3 to 48 hours and the quantification of hydrological hazard fields is done using probability maps of damaging rainstorms prone-areas.

\section{REFERENCE DATA SETS AND METHODOLOGY}

\subsection{Study Area and Problem Setting}

Flood disasters between 1974 and 2003 show Italy and France Countries, including Asiatic regions, among the more vulnerable areas (Fig. 1a). Worldwide is also shown a trend of hydrological disasters strongly increasing (Fig. 1b) (OFDA/CRED International Disaster Database http://www. emdat.be/). These increases are also necessitating a shift from a policy focusing on costly relief assistance to one with more emphasis on mitigation and personal responsibility for living in harm's way. In Fig. (1c) is it also evident as more than $60 \%$ of the nation's natural disasters are a result of weather or climate extremes [20].
The rainstorms most perceived by the public are the large-scale damaging events; however, there is evidence that the most deadly floods are those with short lead times - flash floods - which in Mediterranean Europe have mostly a spatially limited character and can occur far away from major rivers [21]. In this respect, a limited test-area, extending approximately $60000 \mathrm{~km}^{2}$, is chosen across a transitional and complex terrain of Mediterranean central area of the southern Italy (Fig. 2a). In Italy there are different raingauge networks, many of which have been recently grouped under the SCIA-APAT Database (www.apat.it/) that we utilized for collecting ground data. However, ground data are not always updated and not all the networks uniformly coincide at all times with this database. Satellite rain-data were derived from the TRMM-NASA platform, algorithm 3B42 (multisatellite precipitation estimates [22], that uses an optimal combination (HQ) of 2B-31, 2A-12, SSMI, AMSR, and AMSU precipitation estimates, with a resolution of $0.25 \times 0.25$ degree (about $25 \times 25 \mathrm{~km}$ ) grid boxes (http://disc. sci.gsfc.nasa.gov/).

To illustrate the applicability of the proposed methodology, a reference classification was constructed from RHI, driven by rainstorm events on 14 November 2004, 24 January 2003, and 4-5 May 1998. This was necessary because rainfall retrieval TRMM-satellite data were not available prior to 1998 and some ground-gauge data, originating from Italian networks, were unavailable after 2004. Data assimilation pattern in the region under study were obtained from 64 raingauges (Fig. 2a), and 143 supplementary satellite rain grid-data (Fig. 2b).

\subsection{Rainstorm Hazard Problem-Solving Logic Process}

Expert systems can be designed to model processes when carried out using the IF-THEN logic statement to impose an event contingent upon the condition [23]. Problem -solving logic process frameworks include first an invariant spatial model recognizing critical-thresholds from the response ratios between the two following components of the landscape:

a) pulsing force that disturbs the system, including current rainstorm depth, and; 


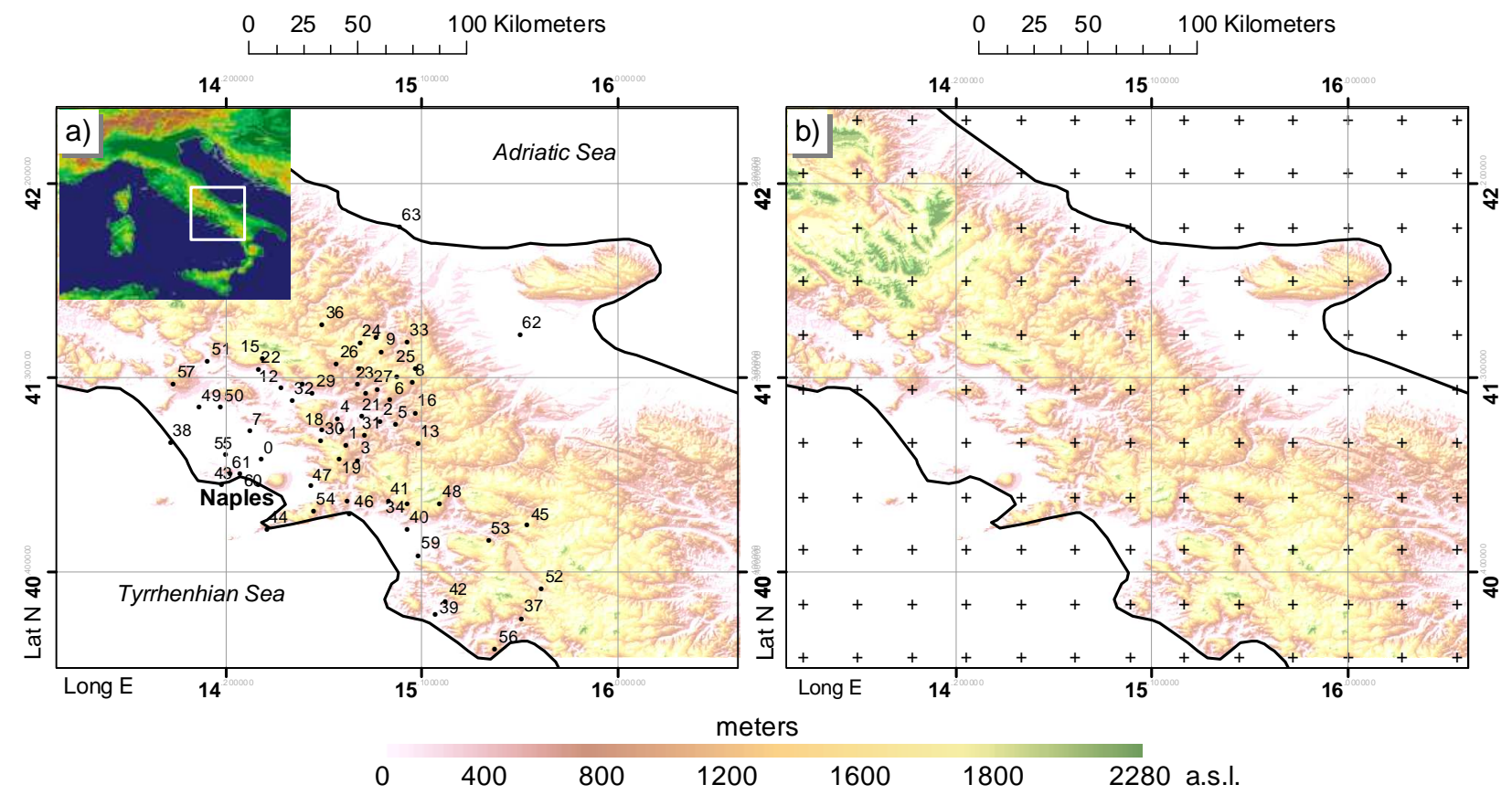

Fig. (2). (a): Geographical setting and data assimilation patterns from in-situ-raingauges with coded-station-points, and (b): TRMM-RS satellite rain data pixel centroid grid of $25 \times 25 \mathrm{~km}$, superimposed on elevation data of hillshade land derived from DEM (SRTM)-90 meters http://srtm.csi.cgiar.org/.

b) resistance force, including storm variability that occurred in the system's climate history.

As a more concrete application, we can incorporate, for each rainy step of duration $h$ at sampled location $\mathbf{s}_{\alpha}$, two processes into the rainstorm logic statement linking the $R H I$ to the following power equation [after 24, 25]:

$\operatorname{RHI}_{h}\left(\mathrm{~s}_{\mathrm{a}}\right)=\max :\left\{\left[\frac{1+R S D_{h}}{f_{(\text {Rclim })}}\right]_{h\left(\mathrm{~s}_{\mathrm{a}}\right)}^{2} \quad \forall \quad h=1 \ldots .48\right.$ hours

where $R S D_{h}$ is the Rain-Storm Depth (mm), that represents the pulsing force that disturbs the system during an event of duration $h$, and:

$f_{(\text {Rclim })}=\operatorname{Med}\left(R S D_{h}\right)-(8-\sqrt{h}) \cdot S_{w e t}$

is a function that represents the system resistance state, that is the intrinsic ability of the system to resist change because of its history (recent and past). $\operatorname{Med}\left(R S D_{h}\right)$-the threshold value - is the median of the annual maximum rainfall $(\mathrm{mm})$ of duration $h$, and the term $(8-\sqrt{ } h) S_{\text {wet }}$, is a function adjusting the threshold value with the current variation of the soil humidity. As proxies of the soil humidity, three coefficients was introduced as $S_{w e t}$ equal to $0.5,0$, and 2 according to dry, humid, and very humid soil conditions before the event, respectively; these coefficients can be derived, in turn from remote sensing; the duration of rainstorm $(h)$ under square root is to explain a major accommodation of the system for rainfall spanning over a longer period. Whereas, for each sampled location with a Rainstorm Hazard Index $(R H I) \rightarrow 0$, no-rainstorm hazard occurs, and with $R H I$ value barely over 1 , the probability of occurrence of a rainstorm hazard commences at 0.50 .

\subsection{Matching Coding Approach for Decision-Making Under Uncertainty}

While the above RHI-model is utilized to arrive at conclusions at the punctual-scale, the use of geostatistics method may help to overcome the inherent difficulties in spatial scaling, when the above $R H I$ discrete data must accommodate a continuous spatial solution and data collection across sampled- and unsampled locations. Thus, the $R H I-$ results are converted to a binary vector and matched to satellite raindata under a GIS flow and supported by indicator cokriging technique (Fig. 3).

Consider the following information obtained over the study area:

- values of the random primary variable $Z(R H I)$, at $\mathrm{m}$ locations $\mathbf{s}_{\alpha}, z\left(\mathbf{s}_{\alpha}\right), \alpha=1,2 \ldots \mathrm{n}_{1}$; and

- $\quad y(\mathbf{s})$ TRMM satellite rain-data at supplementary grid locations $\mathbf{S}$ within the area.

Indicator approach of the primary variable requires that all data be coded as local prior probability values. Precise measurements of $z_{k}$ at hard data locations $\mathbf{s}_{\alpha}$ are then coded into a set of $K$ binary (hard) indicator data defined as:

with $i\left(\mathrm{~s}_{\alpha} ; z_{k}\right)=\left\{\begin{array}{l}1 \rightarrow z\left(\mathrm{~s}_{\alpha}\right)>z_{k} \\ 0 \rightarrow \text { otherwise }\end{array}\right.$

The $z$-values are hard in both senses: (1) they are directly derived from measurements of ground rainfall-data, and (2) are successively transformed into binary vector data. These measurements are often supplemented by a relatively large amount of indirect data, such as those conditioned on remotely sensed spectral response $y(\mathbf{s})$. Each of these data 


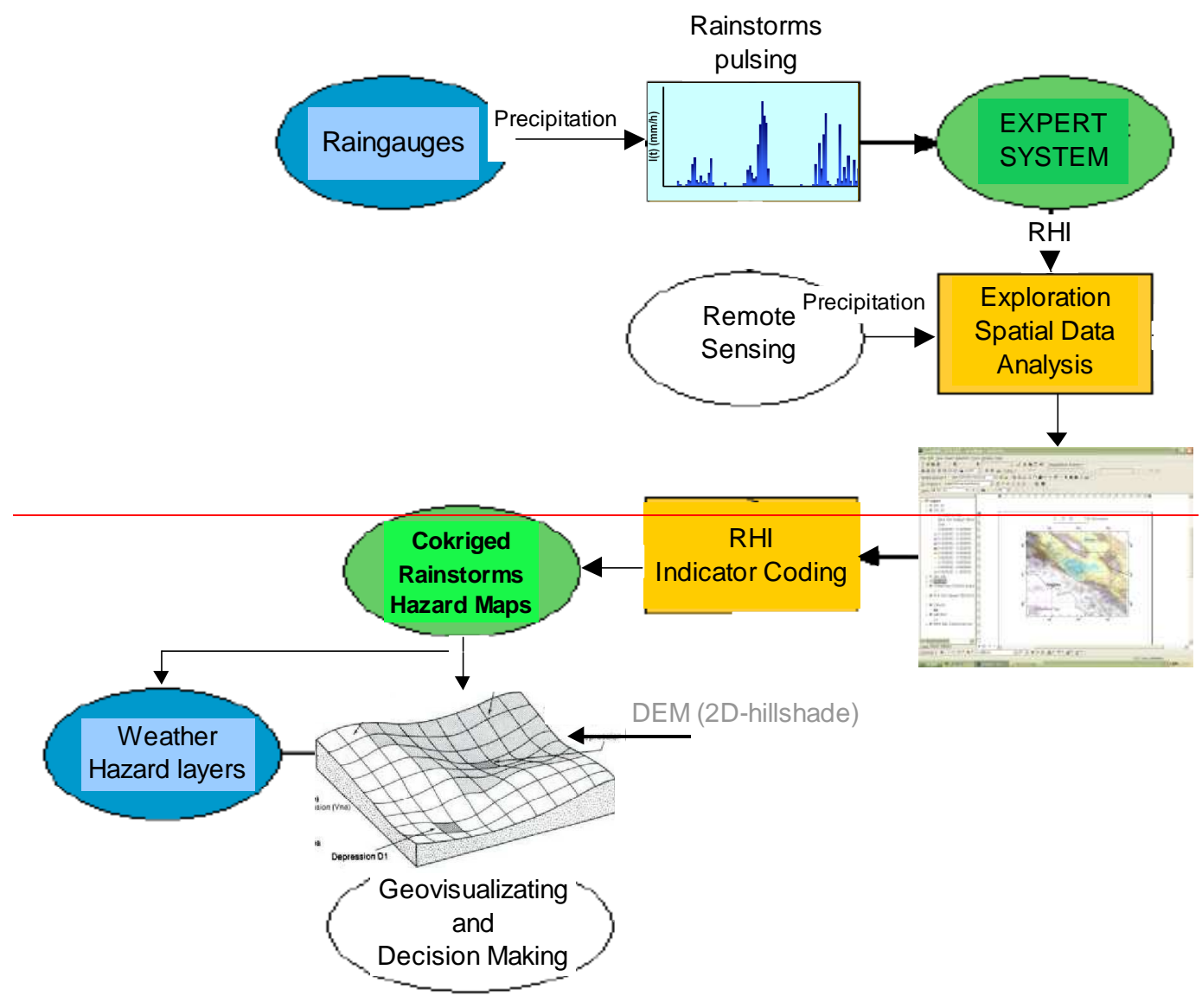

Fig. (3). Flow chart of general process for estimation of rainstorm hazard mapping via GIS rules.

provides only indirect information about the value of the variable $Z$. Using both ground and satellite information such as matching data, the approach is aimed at assessing the probability that the value of $z$ at any unsampled site $\mathbf{s}$ is greater than a given critical $z_{k}$ value. In this way, Indicator CoKriging (ICK) is able to take into account both the information to be processed together, and then used in the ordinary cokriging equations $[26,27]$. To account for both categorial $(R H I)$ and continuous (satellite data), we used standardized variables to produce composite indices compatible to indicator cokriging [27, after 28]. So that, both covariance and cross-covariance functions were applied on the above standardized primary and auxiliary variables for incorporating exhaustively sampled satellite data using the indicator datum that is collocated with the location being estimated. Availability of coregionalization between indicator ground and satellite at critical values of $R H I$ for each location $\mathbf{s}_{\mathrm{o}}$ within the study area allows a grid layer of: the hazard $\alpha\left(\mathbf{s}_{\alpha}\right)$ of declaring a location vulnerable to damage by rainstorms on the basis of the estimate $\left[I\left(\mathrm{~s} ; z_{k}\right)\right]_{\mathrm{oIOK}}{ }^{*}$ when actually $Z(\mathbf{s})$

$>z_{k}=p_{c}($ critical value $=1)$.

\section{RESULTS AND DISCUSSIONS}

\subsection{Rainstorm Hazard Modelling-Control Runs}

In order to validate $R H I$-time evolution, Monte Pino Met European Research Observatory of the TEMS(FAO) Net- work (http://www.fao.org/gtos/tems/tsite_show.jsp?TSITE_ ID=3730) was selected as reference site, because for this location both $R H I-$ data and MDHE database were available. The RHI-control runs depicted in Fig. (4) (blue bars) enable to examine how predicted hazard met landscape response so far referred as MDHE - along 2000-2002 interval. RHI graphs were accompanied by daily or sub-daily rainstorms depth also (black bars in Fig. (4), with scale decreasing), when almost $20 \mathrm{~mm}$ of rain falls.

\subsection{Mapping the Rainstorms Hazard Prone-Areas}

Figs. (5a,b,c) shows high-probability cokriged ( $\mathrm{p}>50 \%)$ maps of areas prone to rainstorm hazards (dark grey zones), and superimposed by areas where multiple damaging hydrological events (MDHE) were observed. It was found that areas with high probability of predicted hazard matched the area actually subject to injurious phenomena, such as severe erosion, landslides, floods, and mudflows. The severity of the damage suffered in these areas was not uniform for each rainstorm level, i.e., the damage observed depended not only on the amount of rainfall but also on the sensitivity of each specific landscape and on soil humidity (others topographical conditions were not considered in this work).

The most extreme hydrogeomorphological processes occur over orographically complex terrain where vegetation is sparse (especially lands that are under autumn tilling, or after the rainy season), and where drainage systems may be obstructed by sediment erosion to contain large volumes of 


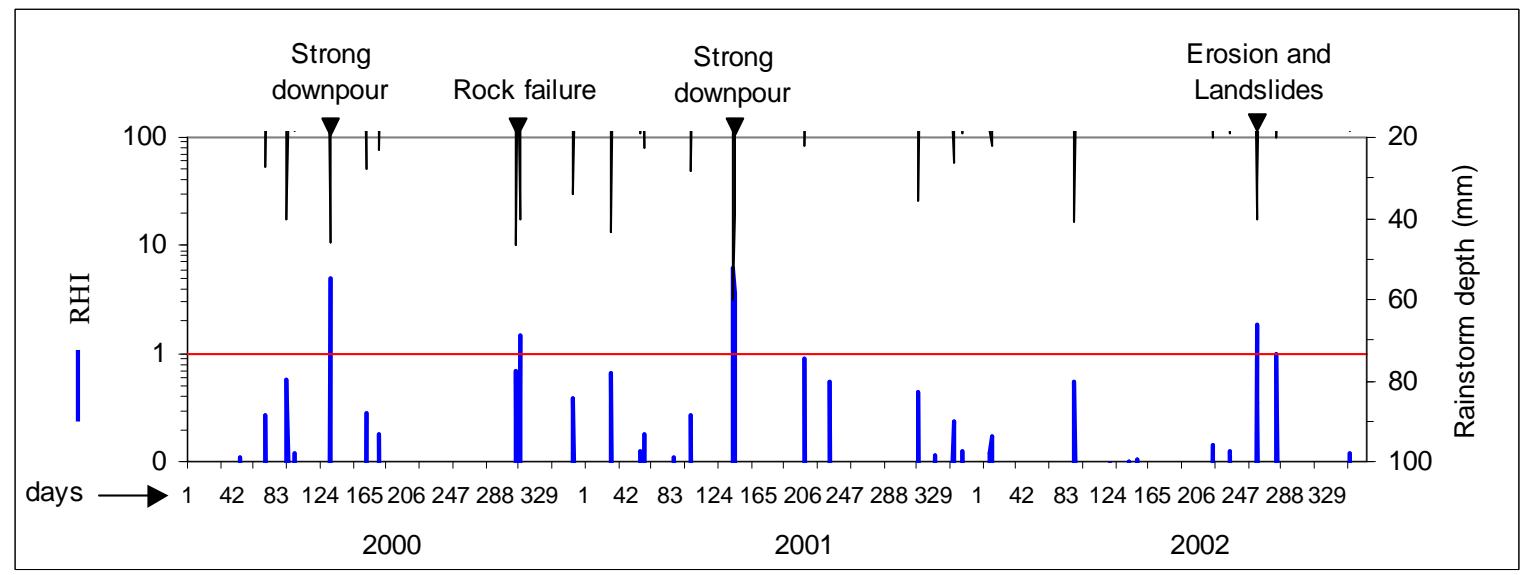

Fig. (4). Daily rainstorms (black bars, with rain $>20 \mathrm{~mm} \mathrm{day}^{-1}$ ), and simulated RHI (blue bars) with associated multiple damaging hydrological events-MDHE ( $\boldsymbol{\nabla}$ ) around Monte Pino Met European Research Observatory during 2000-2002 period. RHI-critical values equal to 1 (alert in red line) is signed too.
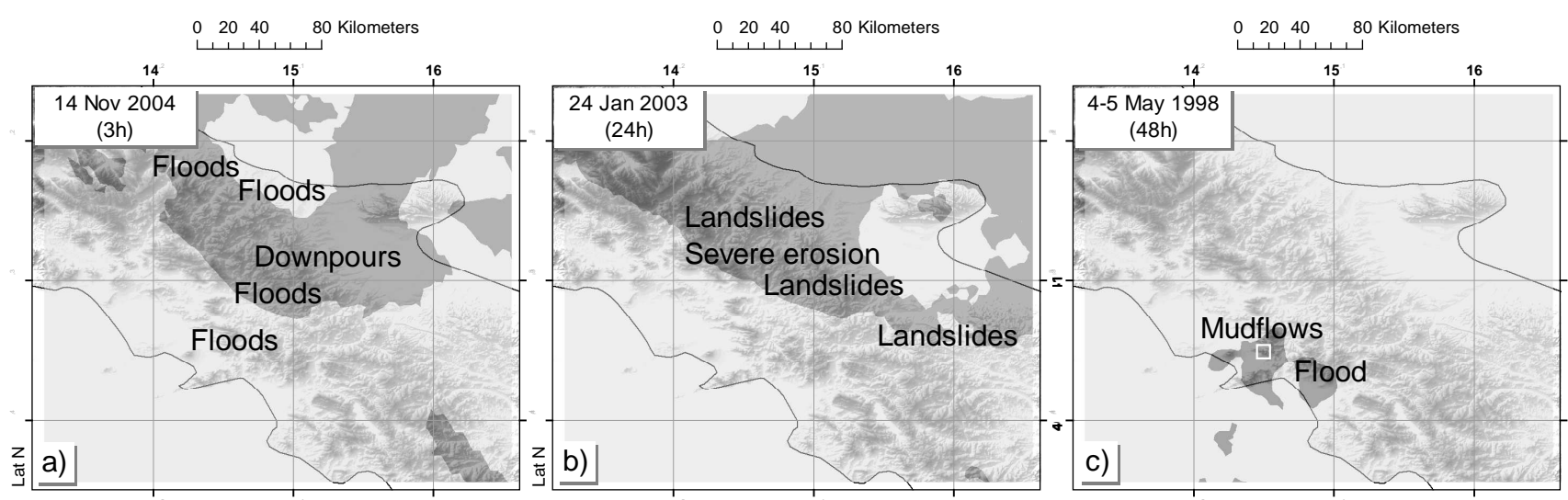

Fig. (5). High-probability ( $p>50 \%$ ) cokriged maps of areas prone to rainstorm hazards (dark grey zone) for rainstorms of duration 3 , 24, and 48 hours (a, b, and c, respectively). Note: the damaging hydrological events superimposed were almost all matched by the cokriged model.

runoff. MDHE are more spatially limited in the period AprilNovember, but more intensive, such as those which occurred on 14 November 2004 (Fig. 5a) and on July 9, 2000 (Fig. not shown).

Although the event of May 4-5, 1998 was expected to be of lower intensity, because of its long duration, the impact was catastrophic at the Sarno location (Campania region), where the several mudflows destroyed over one hundred people (Fig. 5c). This occurred because the meteorological perturbation originated from convective-clouds in larger systems, which are today more dominant in rain-producing mechanisms of high-impact over small areas [29].

On the contrary, MDHE associated to prologed rain usually occur during the winter season only, such as the event that occurred on January 24, 2003, when rainstorm proneareas assumed winding configurations (Fig. 6a). In this respect, an anisotropic neighboring was selected in order to study of the above event of duration of 24 hours, which simulated well the orographic force (rainy-band that lies on the eastern slope of the Apennine chain) driven by the upwind eastern circulations that accompanied the large- and oblong stormy event. Under these conditions, MDHE occurred with landslides and accelerated erosion accompanied by transport of sediment toward the Adriatic coast (Figs. 6b, c). Here, damage were very large and affected lands with different rainstorm depths, ranging from 40 to $100 \mathrm{~mm}$ in 24 hours, and fallen after a precedent rainy period.

However, our results also show that sub-regional rainstorm hazard modelling can provide probability maps for damaging events in Italy with a spatial variability resolution of approximately $20 \mathrm{~km}$. Spatially finer estimates (e.g., at local-scale: $<10 \mathrm{~km}$ ) can be ensured only with the availability of more accurate- and detailed supplementary satelliterain data, although, as noted by [31], all satellite sensors are affected by errors originating from the non-unique, nonlinear relationship of rainfall characteristics to observations and by sampling frequency and sensor resolution issues. 


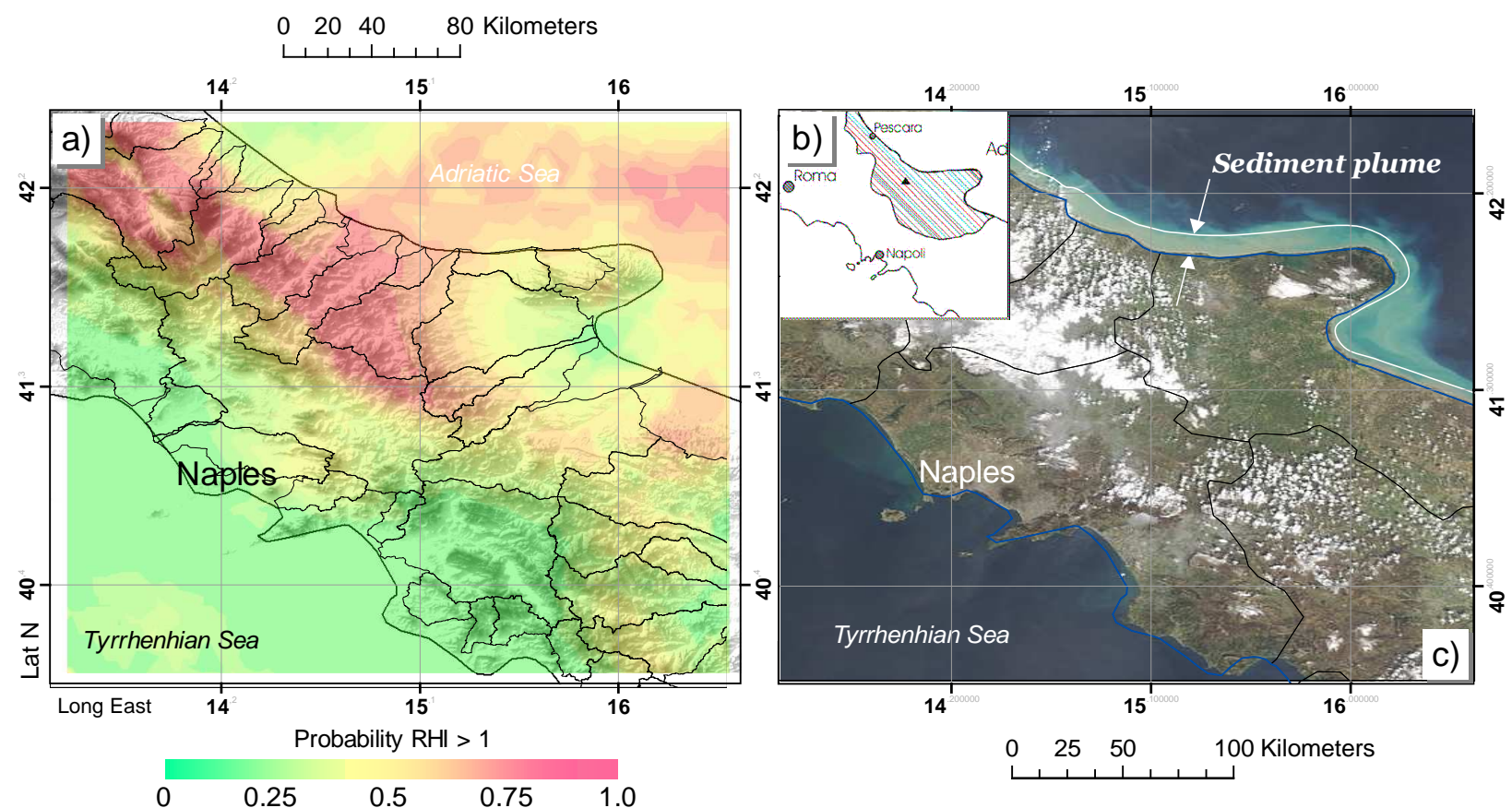

Fig. (6). (a): Cokriged probability map of areas prone to rainstorm hazards for storms of 24 January 2003, and (b): areas afflicted by MDHE (hatched area, from: Fiorillo, 2004) [30], and (c): satellite image after the rainstorm with sediment in Adriatic Sea (sediment plume) deriving from erosive rains fell on the eastern slope of the Apennines (satellite image from NASA: http://visibleearth.nasa.gov/view_rec.php?id=5307/).

\section{CONCLUSIONS}

The model presented here provided the minimum but valuable set of data from which a rough tool for estimating early impacts soon after rainstorms can be derived. Damaging rainstorms collected for this retrospective experiment are documented in the category of localized events (14 November 2004 and 4-5 May 1998), and a major rainstorm large event (3 January 2003). Impact of the damage was determined by an optimum scaling critical value for predicting hazard prone-areas of three rainstorm types, although the $R H I-$ model is capable of performing with data of storms of different intensities. These first results show that subregional rainstorm hazard modelling can provide probability maps for damaging events in Italy with a spatial variability resolution of approximately $20 \mathrm{~km}$. Spatially finer estimates can be ensured only with the availability of more accurateand detailed satellite-rain data, or during forecast stages, if real-time monitoring is implemented on an operational basis, where supplementary satellite information is then replaced by Quantitative Precipitation Forecasting.

\section{REFERENCES}

[1] O. Petrucci, and M. Polemio, "The use of historical data for the characterisation of multiple damaging hydrogeological events", Nat. Hazards Earth Syst. Sci., vol. 3, pp. 17-30, 2003.

[2] B. Kar, and M. E. Hodgson, "A GIS-Based model to determine site suitability of emergency evacuation shelters", Trans. in GIS, vol. 12, pp. 227-248, 2008.

[3] J. Younis, S. Anquetin, and J. Thielen, "The benefit of highresolution operational weather forecasts for flash flood warning", Hydrol. Earth Syst. Sci., vol. 12, pp. 1039-1051, 2008.

[4] M.L. Clarke, and H. M. Rendell, "Climate, extreme events and land degradation", In Extreme Weather Events and Public Health Re- sponses, W. Kirch, B. Menne, and R. Bertollini, Eds. Springer, 2005, pp. 136-152.

[5] M. R. Allen, and W. J. Ingram, "Constraints on future changes in climate and the hydrologic cycle", Nature, vol. 419, pp. 224-231, 2002

[6] M. V .K. Sivakumar, "Impact of natural disasters in agriculture, rangeland and forestry: an overvie", In Natural Disasters and Extreme Events in Agriculture, M. V. K. Sivakumar, R. P. Motha, and H. P. Das, Eds. Springer-Verlag: Berlin, 2005, pp. 1-22.

[7] A. Mazzarella, and N. Diodato, "The alluvial events in the last two Century at Sarno, southern Italy: their classification and power-low time occurrence", Theor. App. Climatol., vol. 72, pp. 75-84, 2002.

[8] D. P. Bacon, N. N. Ahmad, T. J. Dunn, M. C. Montheit, A. Sarma, "An operational multiscale system for hazards prediction, mapping, and response", Nat. Hazards, vol. 44, pp. 317-327, 2008.

[9] T. J. Davis, and C. P. Keller, "Modelling and visualizing multiple spatial uncertainties”, Comput. Geosci., vol. 23, pp. 397-408, 1997.

[10] W. A. Marcus, R. J. Aspinal, and R. A. Marston, "Geographic information systems and surface hydrology in mountains", In Geographical Information Science and Mountain Geomorphology, M. P. Bishop and J. F. Shroder, Jr, Eds. Springer-Praxis Publishing: Chichester, 2004, pp. 343-379.

[11] N. Diodato, "Geostatistical uncertainty modelling for the environmental hazard assessment during single erosive rainstorm events", Environ. Monit. Assess., vol. 105, pp. 25-42, 2005.

[12] E. J. Kelly, N. A. Drake, and S. L. Barr, "Spatial modelling of the terrestrial environment: the coupling of remote sensing with spatial models", In Spatial Modelling of the Terrestrial Environment, E.J. Kelly, N. A. Drake, and S.L. Barr Eds. Wiley \& Sons Ltd: Chichester, 2004, pp. 1-6.

[13] I. Ymeti, "Rainfall estimation by remote sensing for conceptual rainfall-runoff modelling in the upper blue nile basin", M.S. Thesis, International Institute for Geo-information Science and Earth Observation, The Netherlands, 2007.

[14] T. M. Heneker, M. F. Lambert, and G. Kuczera, "A point rainfall model for risk-based design”, J. Hydrol., vol. 247, pp. 54-71, 2001.

[15] M. Pan, E. F. Wood, R. Wojcik, and M. F. McCabe, "Estimation of regional terrestrial water cycle using multi-sensor remote sensing 
observations and data assimilation", Remote Sens. Environ., vol. 112, pp. 1282-1294, 2008.

[16] H. Su, E. F. Wood, H. Wang, and R. T. Pinker, "Spatial and temporal scaling behavior of surface shortwave downward radiation based on MODIS and in situ measurements", Geosci. Remote Sens. Lett. IEEE, vol. 5, pp. 542-546, 2008.

[17] K. Beven, "Models, management and uncertainty: the future of hydrological science", In Rivers Basins-From Hydrological Science to Water Management, I. Tchiguirinskaia, S. Demuth, and P. Hubert, Eds., IAHS Publication No. 323 ISBN 978-1-901502-69-5, $154,2008$.

[18] T. Shoji, and H. Kitaura, "Statistical and geostatistical analysis of rainfall in central Japan", Comput. Geosci., vol. 32, pp. 1007-1024, 2006.

[19] T. R. Allen, S. J. Walsh, D. M. Cairns, J. P. Messina, D. R. Butler, and G. P. Malanson, "Geostatistics and spatial analysis: characterizing form and pattern at the Alpine treeline", In: Geographical Information Science and Mountain Geomorphology, Bishop, M.P., and J. F. Shroder Jr, Eds. Springer-Praxis Publishing: Chichester, 2004, pp. 190-218.

[20] I. Alcántara-Ayala, "Geomorphology, natural hazards, vulnerability and prevention of natural disasters in developing countries", Geomorphology, vol. 47, pp. 107-124, 2002.

[21] M. C. Llasat, T. Rigo, M. Barriendos, "The 'Montserrat-2000' flash flood event: a comparison with the floods that have occurred in the northeast Iberian Peninsula since the 14th century", Int. J. Climatol., vol. 23, pp. 453-469, 2003.

[22] G.J. Huffman, R.F. Adler, D.T. Bolvin, G. Gu, E.J. Nelkin, K.P. Bowman, Y. Hong, E.F. Stocker, and D.B. Wolff, D.B., "The TRMM multi-satellite precipitation analysis: quasi-global, multiyear, combined-sensor precipitation estimates at fine scale", J. Hydrometeorol., vol. 8, pp. 38-55, 2007.
[23] A. Moody, D.B. Katz, "Artificial intelligence in the study of mountain landscapes", In Geographical Information Science and Mountain Geomorphology, M. P. Bishop, M.P., and J. F. Shroder Jr, Ed. Springer-Praxis Publishing: Chichester, 2004, pp. 220-251.

[24] N. Diodato, "Spatial uncertainty modeling of climate processes for extreme hydrogeomorphological events hazard monitoring", ASCE's J. Environ. Eng. vol. 132, pp. 1530-1538, 2006.

[25] N. Diodato, O. Petrucci, and M. Ceccarelli, "Rainstorm hazard problem-solving spatial-time scale invariant process model designing. Geophys. Res. Abstr., vol. 11, EGU2009-4107, 2009.

[26] P. Goovaerts, Ed., Geostatistics for Natural Resources Evaluation, Oxford: Oxford University Press, 1997.

[27] K. Johnston, J. M. Ver Hoef, K. Krivoruchko, and N. Lucas, Eds. Using ArcGis Geostatistical Analyst, New York: ESRI, 2001.

[28] T. Hengle, G. B. M. Heuvelink, and A. Stein, "A generic framework for spatial prediction of soil variables based on regression-kriging", Geoderma, vol. 120, pp. 75-93, 2004.

[29] A. Dünkeloh, and J. Jacobeit, "Circulation dynamics of Mediterranean precipitation variability 1948-1998", Int. J. Clim. vol. 23, pp. 1843-1866, 2003.

[30] F. Fiorillo, "Analysis of rainfall in landslide activation during January-February 2003 in Central-South-Eastern Italy", In: Proceeding of BALWOIS 2004 Ohrid, FY Republic of Macedonia, 2529 May 2004 [Online] Available: http://balwois.com/balwois/administration/full_paper/ffp-1o-158.pdf/. [accessed 10 March 2009].

[31] E. N. Anagnostou, "Overview of overland satellite rainfall estimation for hydro-meteorological applications", Surv. Geophys., vol. 25 , pp. $511-537,2004$

(c) Diodato and Ceccarelli; Licensee Bentham Open.

This is an open access article licensed under the terms of the Creative Commons Attribution Non-Commercial License (http://creativecommons.org/licenses/by-nc/3.0/) which permits unrestricted, non-commercial use, distribution and reproduction in any medium, provided the work is properly cited. 